\title{
Fish consumption and the risk of colorectal cancer: the Ohsaki Cohort Study
}

\author{
Y Sugawara*,', S Kuriyama', M Kakizaki', M Nagai', K Ohmori-Matsuda', T Sone', A Hozawa', Y Nishino² \\ and I Tsuji'
}

'Division of Epidemiology, Department of Public Health and Forensic Medicine, Tohoku University Graduate School of Medicine, Sendai, Japan;

${ }^{2}$ Division of Epidemiology, Miyagi Prefectural Cancer Research Center, Natori, Japan

BACKGROUND: Evidence from laboratory and animal studies suggests that high fish consumption may reduce the risk of colorectal cancer, but the results of studies in humans have been inconsistent. The objective of this study was to prospectively examine the association between fish consumption and the risk of colorectal cancer incidence in Japan, where fish is widely consumed.

METHODS: We analysed data from 39498 men and women registered in the Ohsaki National Health Insurance Cohort Study who were 40-79 years old and free of cancer at the baseline. Fish consumption was assessed at the baseline using a self-administered food frequency questionnaire.

RESULTS: During 9 years of follow-up, we identified 566 incident cases of colorectal cancer (379 men and I87 women). The hazard ratios and $95 \%$ confidence intervals (Cls) for colorectal cancer incidence in the highest quartile of fish consumption compared with the lowest quartile were $1.07(95 \% \mathrm{Cls}$; $0.78-1.46, P$-trend $=0.43)$ for men, and $0.96(95 \% \mathrm{Cls} ; 0.61-1.53, P$-trend $=0.69)$ for women.

CONCLUSION: The results of this prospective cohort study revealed no association between fish consumption and the risk of colorectal cancer.

British Journal of Cancer (2009) I 01, 849-854. doi:I0.1038/sj.bjc.66052I7 www.bjcancer.com

Published online 28 July 2009

(C) 2009 Cancer Research UK

Keywords: fish consumption; colorectal cancer; incidence; prospective cohort study; Japan

In association with marked changes in dietary habits over the last few decades, the incidence of colorectal cancer has been increasing in Japan. In 2002, the world age-standardised incidence rate of colorectal cancer was the second commonest cancer in men $(70.7$ per 100000$)$ and the commonest cancer in women $(38.6$ per 100 000) (Matsuda et al, 2008).

Evidence has suggested associations between consumption of red meat, vegetables, and fruit, and colorectal cancer incidence, but any association with fish consumption is still unclear (World Cancer Research Fund, 2007).

Although laboratory and animal studies suggest that consumption of fish, rich in n-3 fatty acids, inhibits carcinogenesis (Takahashi et al, 1997; Rao et al, 2001), the results of studies in humans have been inconsistent. Most of the previous studies were conducted in countries where fish consumption is relatively low. Japan has the highest fish consumption among the developed countries (Food Balance Sheet, 2003), but only one prospective study has examined the association with colorectal cancer risk in Japan (Kobayashi et al, 2004). Therefore, we analysed data from a large population-based prospective cohort study in Japan.

* Correspondence: Y Sugawara, Division of Epidemiology, Department of Public Health and Forensic Medicine, Tohoku University Graduate School of Medicine, 2-I, Seiryo-machi, Aoba-ku, Sendai, Miyagi 980-8575, Japan; E-mail: yumil717@m.tains.tohoku.ac.jp

Received 26 May 2009; revised 6 July 2009; accepted 6 July 2009; published online 28 July 2009

\section{MATERIALS AND METHODS}

We used data from the Ohsaki National Health Insurance (NHI) Cohort Study, the design of which has been described in detail elsewhere (Tsuji et al, 1998; Kuriyama et al, 2006). Briefly, between October and December 1994, we delivered a self-administered 40 -item food frequency questionnaire (FFQ) to men and women aged 40-79 years old living in the catchment area of Ohsaki Public Health Center, a local government agency providing preventive health services in 14 municipalities in Miyagi Prefecture, northeastern Japan. Among 54996 eligible individuals, 52029 responded to the questionnaire (94.6\%), but 776 who had withdrawn from the NHI before the baseline questionnaire survey were excluded, leaving 51253 (24573 men and 26680 women) in the study cohort. The study protocol was approved by the institutional review board of the Tohoku University School of Medicine. We considered the return of the questionnaire to imply the participant's consent to participate in the study.

The self-administrated questionnaire also covered the personal and family history of diseases, and the lifestyle factors such as smoking status, alcohol consumption, time spent walking per day, job status, marital status, and education. In the FFQ, there were three items relating to fish (i.e., fresh fish, fish products, and dried or salted fish). Fish products were mostly fish paste made from boiled white fish meat (known as 'kamaboko' and 'chikuwa' in Japan). Frequency was in five categories: almost never, 1-2 days per month, 1-2 days per week, 3-4 days per week, or almost every 
day. For seasonal foods, participants were asked to report their intake in the high season. We also collected 12-day dietary records from a subsample of the participants, and determined the portion size for each food item based on the median values in the records. The validity of fresh fish and fish product consumption assessed by the FFQ has been reported earlier (Ogawa et al, 2003). Spearman's correlation coefficients for fresh fish consumption were 0.39 for men and 0.60 for women, and those for fish product consumption were 0.49 for men and 0.41 for women. We did not assess dried or salted fish consumption because the Spearman correlation coefficients indicated a negative correlation. We calculated the weight of total fish consumed each day on the basis of the two items: fresh fish and fish products by multiplying the frequency by the portion size for each fish item; for fresh fish, $95.0 \mathrm{~g} \mathrm{day}^{-1}$ in men and $80.0 \mathrm{gday}^{-1}$ in women, and for fish products, $27.5 \mathrm{~g} \mathrm{day}^{-1}$ in men and $26.7 \mathrm{~g} \mathrm{day}^{-1}$ in women, and summing the two items.

We followed up the participants from 1 June 1995 to 31 December 2003. The end point was diagnosis of colorectal cancer, and the end of follow-up death, emigration, or end of the follow-up period, whichever occurred first. We collected withdrawals from the NHI because of death, emigration, and loss of NHI qualification from the NHI withdrawal history files. We also ascertained incident cases of cancer by computer link with the Miyagi Prefectural Cancer Registry, which covers the study area. In this registry, the percentages registered by death certificates only for colorectal cancer were $7.4 \%$ for men and $11.5 \%$ for women during 1998-2002 (Curado et al, 2007). Cancers were coded according to the International Classification of Diseases for Oncology, 2nd version (ICD-O-2) as colon cancer (C18.2-C18.9) and rectal cancer for the recto-sigmoid junction or rectum combined (C19.0-C20.9), so colorectal cancer was C18.2-C20.9. Furthermore, using hospital records, we classified cancers as localised (within the colon and rectum) or advanced (spread beyond or metastatic involving lymph nodes or other organs).

\section{Statistical analysis}

We excluded participants who had a history of cancer $(N=3155)$, who did not report on fish consumption $(N=8202)$, and who reported extreme values of total daily caloric intake (sex-specific cutoffs for highest $0.5 \%$ and lowest $0.5 \% ; N=398$ ); this left 39498 participants (18 858 men and 20640 women) for this study.

We divided the participants into quartiles on the basis of the weight of total fish consumed (in grams) per day and examined its association with colorectal cancer risk. Person-years of follow-up were estimated for each participant from 1 June 1995 to the end of follow-up. Cox proportional hazards regression analysis was used to estimate the hazard ratios (HRs) and $95 \%$ confidence intervals (CIs) for colorectal cancer incidence according to the lowest quartile of total fish consumption as the reference group, after adjustment for potential confounders. We then divided the participants into tertiles on the basis of the total weight of fish consumed per day and examined the association with total fish consumption.

We also calculated the association between consumption of fresh fish and colorectal cancer incidence. Moreover, we examined the incidence of colorectal cancer classified according to clinical stage (localised or advanced). Colon cancer was also further classified by subsite: ascending (C18.2), transverse (C18.4), descending (C18.6), and sigmoid (C18.7), and the incidence calculated for each site.

We considered the following variables as potential confounders: age (continuous variable), body mass index in $\mathrm{kg} \mathrm{m}^{-2}(<18.5$, $18.5-24.9$, or $\geqslant 25.0$ ), family history of cancer (yes or no), history of stroke (yes or no), history of hypertension (yes or no), history of myocardial infarction (yes or no), history of diabetes mellitus (yes or no), education (junior high school or less, high school, or college/university or higher), marital status (married or unmarried), job status (employed or unemployed), smoking status (never smoked, smoked in the past, currently smoking $<20$ cigarettes day $^{-1}$, or $\geqslant 20$ cigarettes day $^{-1}$ ), alcohol consumption (never drank alcohol, drank in the past, currently drinking), time spent walking $\left(\leqslant 0.5 \mathrm{hday}^{-1}, 0.5-1.0 \mathrm{hday}^{-1}\right.$, or $\left.\geqslant 1 \mathrm{hday}^{-1}\right)$, total caloric intake (continuous variable, $\mathrm{kcal} \mathrm{day}^{-1}$ ), meat consumption (continuous variable, $\mathrm{g} \mathrm{day}^{-1}$ ), vegetable consumption (continuous variable, $\mathrm{g} \mathrm{day}^{-1}$ ), and fruit consumption (continuous variable, $\mathrm{g} \mathrm{day}^{-1}$ ). The $P$-values for the test of linear trend ( $P$-trend) were estimated using the weight of fish (in grams) consumed per day as a continuous variable. The effect modification between total fish consumption and all confounders was tested through the addition of cross-product terms to the multivariate model. All $P$-values were two-sided, and differences at $P<0.05$ were considered statistically significant. All statistical analyses were performed using the SAS statistical software package, version 9.1 (SAS Institute Inc., Cary, NC, USA).

\section{RESULTS}

Table 1 shows the baseline characteristics of the participants according to the quartiles of total fish consumption. Participants with higher fish consumption tended to be older, more likely to walk for more than $1 \mathrm{~h}$, and to have a higher total caloric intake, including meat, vegetables, and fruit. In addition, more than $70 \%$ of men drank alcohol, and over $50 \%$ of men were current smokers. In contrast, $70 \%$ of women had never drunk alcohol or smoked. More men than women had a history of stroke, myocardial infarction, or diabetes mellitus, whereas more women than men had a history of hypertension.

During 305894 person-years of follow-up, 566 incident cases of colorectal cancer (379 men and 187 women) were observed. Table 2 shows the HRs and 95\% CIs of colorectal cancer according to the quartiles of total fish consumption in both men and women. Multivariate analysis showed that total fish consumption was not associated with colorectal cancer incidence in either men or women. The multivariate HRs (95\% CIs) for men in the other groups $v s$ the lowest quartile group were $1.04(0.79-1.39), 1.11$ $(0.81-1.53)$, and $1.07(0.78-1.46)$, respectively $(P$-trend $=0.43)$, whereas those for women were $1.19(0.79-1.81), 1.17(0.73-1.88)$, and $0.96(0.61-1.53)$, respectively $(P$-trend $=0.69)$. Furthermore, separate analyses for colon and rectal cancer, as well as for colorectal cancer overall, showed no association with total fish consumption. For colon cancer, the HRs (95\% CIs) for men and women in the highest fish consumption group were 1.11 $(0.75-1.64 ; P$-trend $=0.27)$ and $0.95(0.53-1.71 ; P$-trend $=0.75)$, respectively. For rectal cancer, the corresponding values were 0.99 $(0.61-1.61 ; P$-trend $=0.95)$ and $0.96(0.47-1.96 ; P$-trend $=0.80)$, respectively. When total fish consumption was divided into tertiles, no association was observed between total fish consumption and colorectal cancer. The multivariate HRs (95\% CIs) for men in the highest $v s$ the other tertiles were $1.10(0.86-1.41)$ and $1.08(0.80-1.46)(P$-trend $=0.43)$, and the corresponding values for women $1.06(0.73-1.55)$ and $0.94(0.63-1.42)(P$-trend $=0.69)$.

Similarly, no association with fresh fish consumption was observed. The multivariate HRs (95\% CIs) for men in the other quartiles $v s$ the lowest quartile were $0.88(0.53-1.46), 0.93$ $(0.57-1.53)$, and $1.03(0.62-1.69)$, respectively $(P$-trend $=0.33)$, whereas the corresponding values for women were 1.58 $(0.67-3.76), 1.54(0.66-3.60)$, and $1.32(0.56-3.15)$, respectively $(P$-trend $=0.54)$. The result was the same when we conducted separate analyses for colon and rectal cancers (data not shown). No significant associations were observed when colorectal cancer was classified by clinical stage. For localised disease, the HR (95\% CIs) for men in the highest group was $1.12(0.72-1.75$; $P$-trend $=0.92)$ and that for women was $0.99(0.50-1.98$; 
Fish consumption and the risk of colorectal cancer

Y Sugawara et al

Table I Characteristics of participants according to fish consumption

\begin{tabular}{|c|c|c|c|c|}
\hline & \multicolumn{4}{|c|}{ Quartile of total fish consumption } \\
\hline & I (low) & 2 & 3 & 4 (high) \\
\hline Men, g day ${ }^{-1}$ & $0-26.2$ & $26.3-53.3$ & $53.4-96.3$ & $\geqslant 96.4$ \\
\hline Number of participants & 5081 & 5611 & 3336 & 4830 \\
\hline Age, years (s.d.) & $56.6(\mid 1.3)$ & $58.0(10.7)$ & $59.3(10.1)$ & $59.6(9.7)$ \\
\hline Body mass index, $\mathrm{kg} \mathrm{m}^{-2}$ (s.d.) & $23.3(3.2)$ & $23.5(2.9)$ & $23.4(3.0)$ & $23.5(2.9)$ \\
\hline Family history of cancer (\%) & 28.6 & 31.3 & 31.5 & 32.1 \\
\hline History of stroke (\%) & 2.5 & 2.1 & 2.7 & 2.3 \\
\hline History of hypertension (\%) & 21.1 & 23.8 & 23.2 & 26.4 \\
\hline History of myocardial infaction (\%) & 3.0 & 2.7 & 3.4 & 3.0 \\
\hline History of diabetes mellitus (\%) & 6.8 & 7.2 & 7.7 & 8.0 \\
\hline \multicolumn{5}{|l|}{ Education (\%) } \\
\hline Junior high school or less & 49.0 & 50.2 & 56.2 & 58.5 \\
\hline High school & 39.0 & 39.6 & 34.8 & 34.4 \\
\hline College/university or higher & 12.0 & 10.2 & 9.0 & 7.1 \\
\hline \multicolumn{5}{|l|}{ Marital status (\%) } \\
\hline Married & 86.5 & 89.8 & 91.2 & 92.2 \\
\hline Unmarried & 13.5 & 10.2 & 8.8 & 7.8 \\
\hline \multicolumn{5}{|l|}{ Job status (\%) } \\
\hline Employed & 80.0 & 79.6 & 78.9 & 81.8 \\
\hline Unemployed & 20.0 & 20.4 & 21.1 & 18.2 \\
\hline \multicolumn{5}{|l|}{ Smoking status (\%) } \\
\hline Never smoked & 17.4 & 20.3 & 19.4 & 22.1 \\
\hline Smoked in the past & 23.8 & 27.5 & 26.6 & 28.5 \\
\hline Currently smoking, $<20$ cigarettes day $^{-1}$ & 17.4 & 15.5 & 17.2 & 17.2 \\
\hline Currently smoking, $\geqslant 20$ cigarettes day $^{-1}$ & 41.4 & 36.7 & 36.8 & 32.2 \\
\hline \multicolumn{5}{|l|}{ Alcohol consumption (\%) } \\
\hline Never drank alcohol & 18.8 & 15.5 & 14.9 & 13.4 \\
\hline Drank in the past & 9.8 & 9.7 & 9.9 & 8.8 \\
\hline Currently drinking & 71.4 & 74.8 & 75.2 & 77.8 \\
\hline \multicolumn{5}{|l|}{ Time spent walking (\%) } \\
\hline$\leqslant 0.5$ h day $^{-1}$ & 33.6 & 28.4 & 26.9 & 25.0 \\
\hline $0.5-1.0$ h day $^{-1}$ & 25.0 & & 25.1 & 23.4 \\
\hline$\geqslant 1$ h day $^{-1}$ & 41.4 & 45.9 & 48.0 & 51.6 \\
\hline Total caloric intake, kcal (s.d.) & $1645.8(562.4)$ & $1832.6(557.2)$ & $1931.7(577.9)$ & $2083.7(579.7)$ \\
\hline Meat consumption, g (s.d.) & $18.2(13.9)$ & $21.6(14.6)$ & $22.0(18.1)$ & $27.3(20.7)$ \\
\hline Vegetable consumption, g (s.d.) & $36.1(28.2)$ & $48.0(29.8)$ & $55.0(34.0)$ & $65.2(35.2)$ \\
\hline Fruit consumption, g (s.d.) & $57.7(50.3)$ & $76.0(52.8)$ & $83.1(56.6)$ & $96.8(57.2)$ \\
\hline Women, gday $^{-1}$ & $0-26.6$ & $26.7-45.7$ & $45.8-81.3$ & $\geqslant 81.4$ \\
\hline Number of participants & 4752 & 6259 & 3611 & 6018 \\
\hline Age, years (s.d.) & $59.6(11.0)$ & $59.3(10.4)$ & $60.7(9.9)$ & $60.8(9.2)$ \\
\hline Body mass index, $\mathrm{kg} \mathrm{m}^{-2}$ (s.d.) & $23.7(3.6)$ & $23.7(3.3)$ & $23.7(3.2)$ & $23.9(3.3)$ \\
\hline Family history of cancer (\%) & 32.1 & 34.4 & 35.2 & 34.3 \\
\hline History of stroke (\%) & 2.0 & 1.4 & 0.7 & 1.0 \\
\hline History of hypertension (\%) & 25.2 & 26.8 & 26.6 & 28.5 \\
\hline History of myocardial infaction (\%) & 1.7 & 1.6 & 1.7 & 2.3 \\
\hline History of diabetes mellitus (\%) & 5.4 & 5.0 & 5.5 & 5.1 \\
\hline \multicolumn{5}{|l|}{ Education (\%) } \\
\hline Junior high school or less & 52.7 & 45.8 & 49.6 & 49.3 \\
\hline High school & 36.4 & 43.2 & 39.4 & 41.3 \\
\hline College/university or higher & 10.9 & 11.0 & 11.0 & 9.4 \\
\hline \multicolumn{5}{|l|}{ Marital status (\%) } \\
\hline Married & 71.1 & 76.5 & 78.2 & 79.3 \\
\hline Unmarried & 28.9 & 23.5 & 21.8 & 20.7 \\
\hline \multicolumn{5}{|l|}{ Job status (\%) } \\
\hline Employed & 44.9 & 47.0 & 44.4 & 47.9 \\
\hline Unemployed & 55.1 & 53.0 & 55.6 & 52.1 \\
\hline \multicolumn{5}{|l|}{ Smoking status (\%) } \\
\hline Never smoked & 85.7 & 90.2 & 91.3 & 94.0 \\
\hline Smoked in the past & 2.8 & 2.7 & 1.9 & 2.0 \\
\hline Currently smoking, $<20$ cigarettes day $^{-1}$ & 7.4 & 4.8 & 4.7 & 2.7 \\
\hline Currently smoking, $\geqslant 20$ cigarettes day $^{-1}$ & 4.1 & 2.3 & 2.1 & 1.3 \\
\hline \multicolumn{5}{|l|}{ Alcohol consumption (\%) } \\
\hline Never drank alcohol & 70.1 & 71.7 & 73.0 & 76.0 \\
\hline Drank in the past & 5.7 & 4.5 & 3.6 & 3.1 \\
\hline Currently drinking & 24.2 & 23.8 & 23.4 & 20.9 \\
\hline
\end{tabular}


follow-up. We also conducted stratified analyses according to age and other potential confounders but found no associations with total fish consumption (data not shown). Furthermore, effect modification was tested with all confounders, but significant effect modifications were observed only with total fish consumption.

\section{DISCUSSION}

In this population-based cohort study in Japan, we found no significant associations between fish consumption and the incidence of colorectal cancer. In the 20 prospective studies that have examined this question, eight reported an inverse (Willett et al, 1990; Bostick et al, 1994; Goldbohm et al, 1994; Gaard et al, 1996; Kato et al, 1997; Tiemersma et al, 2002; Norat et al, 2005; Hall et al, 2008), 1 reported a positive (Knekt et al, 1999), and the remaining 11 reported no association (Giovannucci et al, 1994; Pietinen et al, 1999; Ma et al, 2001; English et al, 2004; Kobayashi et al, 2004; Lin et al, 2004; Sanjoaquin et al, 2004; Larsson et al, 2005; Lüchtenborg et al, 2005; Engeset et al, 2007; Lee et al, 2009). Our result is consistent with the latter 11 studies.

In only three of the eight studies reporting an inverse association was this statistically significant (Kato et al, 1997; Norat et al, 2005; Hall et al, 2008). There are several possible reasons for the discrepancy between our finding and the latter three studies. First, the weight of fish consumed daily differed among the study populations. In fact, this was only about onethird of that in our study (Food Balance Sheet, 2003). Second, the fish species consumed would have differed among the study populations. In our study there was a high intake of tuna, mackerel, and sardine, which contain high levels of n-3 fatty acids, whereas the other studies had higher intakes of salmon, cod, and herring (Food Balance Sheet, 2003). If the results were influenced by fish species, the association between fish consumption and the incidence of colorectal cancer might appear more strongly in our study population because our study population had a high intake of fish which contain high levels of n-3 fatty acids. However, we observed no association with total fish consumption, suggesting that the difference in fish species did not explain the discrepancy with other studies. Third, high fish consumers in Western countries may be more health-conscious individuals, and as there was no adjustment for potential confounding by vegetable or fruit consumption, this remains a possibility.

One study from Finland reported an increased incidence of colon cancer that was attributed to smoked and salted fish (Knekt et al, 1999), but the cooking methods may have influenced the results.

Our study had several strengths including recruitment of individuals from the general population and the occurrence of a larger number of colorectal cancer cases (566) than recent prospective studies. Second, the response rate was high $(94.6 \%)$ and the selection bias was small. Third, our study population was in Japan, which has the highest fish consumption in the world (Food Balance Sheet, 2003).

The first of the limitations is that we collected information on fish consumption frequency only once and by a self-reported questionnaire. Therefore, some misclassification of exposure would have been inevitable, and the reported HR was likely to have underestimated the true relationship, although the questionnaire was validated (Ogawa et al, 2003). Second, dried or salted fish consumption was not included in our estimate of total fish consumption, so actual total fish consumption may have been underestimated. However, the portion sizes of dried or salted fish calculated by a validated study were small $\left(10 \mathrm{~g} \mathrm{day}^{-1}\right.$, among both men and women). Third, we were unable to check whether the use of aspirin or anti-inflammatory drugs influenced the association with fish consumption (Chan et al, 2005). However, as the Japanese hardly ever use aspirin or anti-inflammatory drugs on a prophylactic basis, the probability of such confounding was probably low.

In conclusion, this prospective study has found that total fish consumption is not associated with the incidence of colorectal cancer in Japan.

\section{ACKNOWLEDGEMENTS}

This study was supported in part by Grants-in-Aid for Cancer Research and for the Third Term Comprehensive Ten-Year Strategy for Cancer Control (H18-3jigan-ippan-001, H21-3jiganippan-003), Ministry of Health, Labour and Welfare, Japan.

\section{REFERENCES}

Bostick RM, Potter JD, Kushi LH, Sellers TA, Steinmetz KA, McKenzie DR, Gapstur SM, Folsom AR (1994) Sugar, meat, and fat intake, and nondietary risk factors for colon cancer incidence in Iowa women (United States). Cancer Causes Control 5: 38-52

Chan AT, Giovannucci EL, Meyerhardt JA, Schernhammer ES, Curhan GC, Fuchs CS (2005) Long-term use of aspirin and nonsteroidal antiinflammatory drugs and risk of colorectal cancer. JAMA 294: 914-923

Curado M, Edwards B, Shin H, Storm H, Ferlay J, Heanue M, Boyle P (2007) Cancer Incidence in Five Continents, Vol.IX. In: IARC Scientific Publications. IARC: Lyon

Engeset D, Andersen V, Hjartåker A, Lund E (2007) Consumption of fish and risk of colon cancer in the Norwegian Women and Cancer (NOWAC) study. Br J Nutr 98: 576-582

English DR, MacInnis RJ, Hodge AM, Hopper JL, Haydon AM, Giles GG (2004) Red meat, chicken, and fish consumption and risk of colorectal cancer. Cancer Epidemiol Biomarkers Prev 13: 1509-1514

Food Balance Sheet (2003) FAO. http://faostat.fao.org/site/610/DesktopDefault. aspx?PageID $=610 \#$ ancor (Accessed 14 May 2009)

Gaard M, Tretli S, Loken EB (1996) Dietary factors and risk of colon cancer: a prospective study of 50535 young Norwegian men and women. Eur J Cancer Prev 5: 445-454

Giovannucci E, Rimm EB, Stampfer MJ, Colditz GA, Ascherio A, Willett WC (1994) Intake of fat, meat, and fiber in relation to risk of colon cancer in men. Cancer Res 54: 2390-2397
Goldbohm RA, van den Brandt PA, van 't Veer P, Brants HA, Dorant E, Sturmans F, Hermus RJ (1994) A prospective cohort study on the relation between meat consumption and the risk of colon cancer. Cancer Res 54: 718-723

Hall MN, Chavarro JE, Lee IM, Willett WC, Ma J (2008) A 22-year prospective study of fish, n-3fatty acid intake, and colorectal cancer risk in men. Cancer Epidemiol Biomarkers Prev 17: 1136-1143

Kato I, Akhmedkhanov A, Koenig K, Toniolo PG, Shore RE, Riboli E (1997) Prospective study of diet and female colorectal cancer: the NewYork University Women's Health Study. Nutr Cancer 28: 276-281

Knekt P, Jarvinen R, Dich J, Hakulinen T (1999) Risk of colorectal and other gastro-intestinal cancers after exposure to nitrate, nitrite and N-nitroso compounds: a follow-up study. Int J Cancer 80: 852-856

Kobayashi M, Tsubono Y, Otani T, Hanaoka T, Sobue T, Tsugane S (2004) Fish, long-chain $n-3$ polyunsaturated fatty acids, and risk of colorectal cancer in middle-aged Japanese: the JPHC study. Nutr Cancer 49: 32-40

Kuriyama S, Shimazu T, Ohmori K, Kikuchi N, Nakaya N, Nishino Y, Tsubono Y, Tsuji I (2006) Green tea consumption and mortality due to cardiovascular disease, cancer, and all causes in Japan: The Ohsaki study. JAMA 296: $1255-1265$

Larsson SC, Rafter J, Holmberg L, Bergkvist L, Wolk A (2005) Red meat consumption and risk of cancers of the proximal colon, distal colon and rectum: the Swedish Mammography Cohort. Int J Cancer 113: $829-834$ 
Lee SA, Shu XO, Yang G, Li H, Gao YT, Zheng W (2009) Animal origin foods and colorectal cancer risk: a report from the Shanghai Women's Health Study. Nutr Cancer 61: 194-205

Lin J, Zhang SM, Cook NR, Lee IM, Buring JE (2004) Dietary fat and fatty acids and risk of colorectal cancer in women. Am J Epidemiol 160: $1011-1022$

Lüchtenborg $M$, Weijenberg $M P$, de Goeij AF, Wark PA, Brink M, Roemen GM, Lentjes MH, de Bruïne AP, Goldbohm RA, van 't Veer P, van den Brandt PA (2005) Meat and fish consumption, APC gene mutations and hMLH1 expression in colon and rectal cancer: prospective cohort study (The Netherlands). Cancer Causes Control 16: $1041-1054$

Ma J, Giovannucci E, Pollak M, Chan JM, Gaziano JM, Willett W, Stampfer MJ (2001) Milk intake, circulating levels of insulin-like growth factor-I, and risk of colorectal cancer in men. J Natl Cancer Inst 93: $1330-1336$

Matsuda T, Marugame T, Kamo K, Katanoda K, Ajiki W, Sobue T, The Japan Cancer Surveillance Research Group (2008) Cancer incidence and incidence rates in Japan in 2002: based on data from 11 population-based cancer registries. Jpn J Clin Oncol 38: 641-648

Norat T, Bingham S, Ferrari P, Slimani N, Jenab M, Mazuir M, Overvad K, Olsen A, Tjønneland A, Clavel F, Boutron-Ruault MC, Kesse E, Boeing H, Bergmann MM, Nieters A, Linseisen J, Trichopoulou A, Trichopoulos D, Tountas Y, Berrino F, Palli D, Panico S, Tumino R, Vineis P, Buenode-Mesquita HB, Peeters PH, Engeset D, Lund E, Skeie G, Ardanaz E, González C, Navarro C, Quirós JR, Sanchez MJ, Berglund G, Mattisson I, Hallmans G, Palmqvist R, Day NE, Khaw KT, Key TJ, San Joaquin M, Hémon B, Saracci R, Kaaks R, Riboli E (2005) Meat, fish, and colorectal cancer risk: the European Prospective Investigation into Cancer and Nutrition. J Natl Cancer Inst 97: 906 -916

Ogawa K, Tsubono Y, Nishino Y, Watanabe Y, Ohkubo T, Watanabe T, Nakatsuka H, Takahashi N, Kawamura M, Tsuji I, Hisamichi S (2003)
Validation of a food-frequency questionnaire for cohort studies in rural Japan. Public Health Nut 6: 147-157

Pietinen P, Malila N, Virtanen M, Hartman TJ, Tangrea JA, Albanes D, Virtamo J (1999) Diet and risk of colorectal cancer in a cohort of Finnish men. Cancer Causes Control 10: 387-396

Rao CV, Hirose Y, Indranie C, Reddy BS (2001) Modulation of experimental colon tumorigenesis by types and amounts of dietary fatty acids. Cancer Res 61: $1927-1933$

Sanjoaquin MA, Appleby PN, Thorogood M, Mann JI, Key TJ (2004) Nutrition, lifestyle and colorectal cancer incidence: a prospective investigation of 10998 vegetarians and non-vegetarians in the United Kingdom. Br J Cancer 90: 118-121

Takahashi M, Fukutake M, Isoi T, Fukuda K, Sato H, Yazawa K, Sugimura T, Wakabayashi K (1997) Suppression of azoxymethane-induced rat colon carcinoma development by a fish oil component, docosahexaenoic acid (DHA). Carcinogenesis 18: $1337-1342$

Tiemersma EW, Kampman E, Bueno de Mesquita HB, Bunschoten A, van Schothorst EM, Kok FJ, Kromhout D (2002) Meat consumption, cigarette smoking, and genetic susceptibility in the etiology of colorectal cancer: results from a Dutch prospective study. Cancer Causes Control 13: 383 - 393

Tsuji I, Nishino Y, Ohkubo T, Kuwahara A, Ogawa K, Watanabe Y, Tsubono Y, Bando T, Kanemura S, Izumi Y, Sasaki A, Fukao A, Nishikori M, Hisamichi S (1998) A prospective cohort study on National Health Insurance beneficiaries in Ohsaki, Miyagi Prefecture, Japan: study design, profiles of the subjects and medical cost during the first year J Epidemiol 8: 258-263

Willett WC, Stampfer MJ, Colditz GA, Rosner BA, Speizer FE (1990) Relation of meat, fat, and fiber intake to the risk of colon cancer in a prospective study among women. N Engl J Med 323: $1664-1672$

World Cancer Research Fund (2007) Food, Nutrition, Physical Activity, and the Prevention of Cancer: A Global Perspective. American Institute for Cancer Research: Washington, DC 